\title{
Two cases of amiodarone-induced thyrotoxicosis successfully treated with a short course of antithyroid drugs while amiodarone was continued
}

\author{
Mieke D Trip, Donald R Düren, Wilmar M Wiersinga
}

\begin{abstract}
Two patients with amiodarone-induced thyrotoxicosis were treated successfully with potassium perchlorate and carbimazole while treatment with amiodarone was continued. These antithyroid drugs were stopped after the patients had became clinically and biochemically euthyroid. During follow up, when treatment with amiodarone continued, thyrotoxicosis did not recur.

Amiodarone-induced thyrotoxicosis seems to be a transient condition that can be treated successfully with a short course of antithyroid drugs without stopping amiodarone treatment.
\end{abstract}

(Br Heart F 1994;72:266-268)

Amiodarone is an effective antiarrhythmic agent with a high iodine content that affects the production and secretion of thyroid hormones and in some patients induces overt thyrotoxicosis or hypothyroidism. The mechanism responsible is incompletely understood. An iodine excess is not the prime determinant. ${ }^{1}$ Amiodarone could induce hypothyroidism by unmasking a pre-existing subclinical abnormality.

Amiodarone induced thyrotoxicosis is unpredictable with an unexplained sudden onset in patients with previously normal thyroid function and without pre-existing thyroid antibodies. The chief hypothesis for the pathogenesis of amiodarone induced thyrotoxicosis is that amiodarone or its metabolites damage the thyroid cells and disrupt follicles, resulting in the release of thyroid hormones into the circulation. ${ }^{2}$ This hypothesis implies that treatment with amiodarone must be stopped. This may result in the recurrence of the life-threatening tachycardia. Martino et al reported that stopping amiodarone treatment and starting treatment with potassium perchlorate and methimazole led to a resolution of thyrotoxicosis within 16-36 days. ${ }^{3}$ Reichert et al reported the successful treatment of amiodarone induced thyrotoxicosis with potassium perchlorate and methimazole, while treatment with amiodarone was continued, in three patients. ${ }^{4}$ These patients became euthyroid in 2-5 weeks. Then they were treated with a combination of amiodarone and methimazole.

We report two patients in whom amiodarone induced thyrotoxicosis was successfully treated with potassium perchlorate and carbimazole while treatment with amiodarone was continued.

\section{Case reports}

CASE 1 (TABLE 1)

A man aged 18 presented in 1985 with ventricular flutter caused by arrhythmogenic right ventricular dysplasia. The tachycardia did not respond to several antiarrhythmic drugs. Treatment with amiodarone (400 mg/day) was started in 1988 . There were no further recurrences of tachycardia. Before treatment with amiodarone was started the patient was clinically euthyroid, with no goitre and concentrations of thyroid hormones within normal range and no thyroid autoantibodies.

Two years later he attended the outpatient
Department of Cardiology, Academic Medical Center, Amsterdam, The Netherlands M D Trip

D R Düren

Department of

Endocrinology

W M Wiersinga

Correspondence to Dr Mieke D Trip,

Dr Mieke D Trip, Academic Medical Cente Meibergdreef 9 , Amsterdam,

Accepted for publication 28 March 1994
Table 1 Clinical state and hormone concentrations in patient 1

\begin{tabular}{|c|c|c|c|c|c|c|c|c|}
\hline Time (mth) & 0 & 15 & 28 & 31 & 33 & 35 & 37 & 55 \\
\hline Clinic & EU & EU & $\begin{array}{l}\text { EU } \\
\text { goiter }\end{array}$ & $\begin{array}{l}\mathrm{EU} \\
\mathrm{BH}\end{array}$ & AIT & EU & $\begin{array}{l}\text { EU TSH } \\
\text { normal }\end{array}$ & $\begin{array}{l}\text { EU } \\
\text { VT }\end{array}$ \\
\hline Treatment & start A & & & & start $\mathrm{C}+\mathrm{K}$ & $C+K$ & $\mathrm{C}+\mathrm{K}$ stop & \\
\hline $\begin{array}{l}\text { Serum amiodarone } \mathrm{mmol} / 1 \\
\text { Serum desethylamiodarone } \mathrm{mmol} / /\end{array}$ & - & $\begin{array}{l}0.70 \\
0.45\end{array}$ & $\begin{array}{l}1.2 \\
0.85\end{array}$ & & $\begin{array}{l}1.5 \\
0.7\end{array}$ & & $\begin{array}{l}0.9 \\
0.9\end{array}$ & $\begin{array}{l}0 \cdot 2 \\
0 \cdot 4\end{array}$ \\
\hline $\begin{array}{l}\text { TSH mU/l } \\
\text { T4 (nmol/l) } \\
\text { FT4 (pmol/l) } \\
\text { T3 (nmol/l) } \\
\text { rT3 (nmoll) } \\
\text { TG (ng/ml) } \\
\text { TgAb McAb }\end{array}$ & $\begin{array}{l}5 \cdot 4 \\
95 \\
13 \cdot 3 \\
15 \cdot 0 \\
0 \cdot 24 \\
32\end{array}$ & $\begin{array}{l}1 \cdot 8 \\
160 \\
20 \cdot 8 \\
1 \cdot 75 \\
0 \cdot 75 \\
175 \\
-1-\end{array}$ & $\begin{array}{c}3.6 \\
145 \\
21.0 \\
1.55 \\
0.77 \\
380\end{array}$ & $\begin{array}{l}<0 \cdot 1 \\
215\end{array}$ & $\begin{array}{c}<0 \cdot 1 \\
260 \\
59 \cdot 8 \\
3 \cdot 10 \\
1 \cdot 10 \\
1700 \\
-1-\end{array}$ & $\begin{array}{c}<0 \cdot 1 \\
170 \\
25.5 \\
2.30 \\
0.84 \\
820\end{array}$ & $\begin{array}{c}1 \cdot 6 \\
110 \\
17 \cdot 0 \\
1 \cdot 00 \\
0 \cdot 56 \\
200 \\
-1-\end{array}$ & $\begin{array}{c}6.0 \\
115 \\
18.4 \\
1.55 \\
0.35 \\
110\end{array}$ \\
\hline
\end{tabular}

AIT, amiodarone induced thyrotoxicosis; C, carbimazol; EU, euthyroid (clinical); FT4, free T4; K, potassium perchlorate $\mathrm{McAb}$, microsomal antibodies; $\mathrm{rT} 3$, reverse T3; T3, triiodothyronine; T4, thyroxine; $\mathrm{TgAb}$, thyroglobuline antibodies; $\mathrm{TSH}$, thyroid stimulating hormone. 
Table 2 Clinical state and hormone concentrations in patient 2

\begin{tabular}{|c|c|c|c|c|c|c|c|}
\hline Time (mth) & 0 & 13 & 37 & 38 & 40 & 44 & 49 \\
\hline $\begin{array}{l}\text { Clinic } \\
\text { Treatment }\end{array}$ & $\begin{array}{l}\text { EU } \\
\text { start A }\end{array}$ & EU & AIT & $\begin{array}{l}\mathrm{AIT} \\
\text { start } \mathrm{C}+\mathrm{K}\end{array}$ & $\begin{array}{l}\mathrm{EU} \\
\mathrm{C}+\mathrm{K}\end{array}$ & $\begin{array}{l}\text { EU TSH normal } \\
\mathrm{C}+\mathrm{K} \text { stop }\end{array}$ & $\mathbf{E U}$ \\
\hline $\begin{array}{l}\text { Serum amiodarone (mmol/l) } \\
\text { Serum desethylamiodarone }\end{array}$ & - & $\begin{array}{l}2 \cdot 1 \\
0 \cdot 67\end{array}$ & & $\begin{array}{l}2.0 \\
2.01\end{array}$ & $\begin{array}{l}2 \cdot 7 \\
2 \cdot 5\end{array}$ & $\begin{array}{l}3 \cdot 0 \\
2 \cdot 2\end{array}$ & $\begin{array}{l}3 \cdot 2 \\
2 \cdot 4\end{array}$ \\
\hline $\begin{array}{l}\text { TSH (mu/l) } \\
\text { T4 (nmol/l) } \\
\text { FT4 (pmol/l) } \\
\text { T3 (nmol/l) } \\
\text { rT3 (nmol/l) } \\
\text { TG (ng/ml) } \\
\text { TgAb McAb }\end{array}$ & $\begin{array}{l}0 \cdot 5 \\
115 \\
1 \cdot 75 \\
0 \cdot 44 \\
13\end{array}$ & $\begin{array}{l}1 \cdot 5 \\
194 \\
32 \cdot 3 \\
1 \cdot 45 \\
0 \cdot 80 \\
9 \\
-1-\end{array}$ & $\begin{array}{l}<0 \cdot 1 \\
395 \\
79 \\
2 \cdot 68 \\
1 \cdot 30 \\
140\end{array}$ & $\begin{array}{l}<0 \cdot 1 \\
340 \\
54 \cdot 4 \\
1 \cdot 68 \\
55 \\
-1-\end{array}$ & $\begin{array}{c}<0 \cdot 1 \\
290 \\
37 \cdot 7 \\
2 \cdot 00 \\
1 \cdot 12 \\
38\end{array}$ & $\begin{array}{c}0 \cdot 4 \\
270 \\
29 \cdot 7 \\
1 \cdot 50 \\
0 \cdot 77 \\
44 \\
-1-\end{array}$ & $\begin{array}{c}3 \cdot 1 \\
265 \\
29 \cdot 2 \\
1 \cdot 60 \\
0 \cdot 72 \\
95\end{array}$ \\
\hline
\end{tabular}

AIT, amiodarone induced thyrotoxicosis; C, carbimazol; EU, euthyroid (clinical); FT4, free T4; K, potassium perchlorate; McAb, microsomal antibodies; $\mathrm{rT3}$, reverse T3; T3, triiodothyronine; T4, thyroxine; TgAb, thyroglobuline antibodies TSH, thyroid stimulating hormone.

department complaining of dysphagia. The physical examination showed no evidence of hypothyroidism but a tender diffuse goitre was palpable. Thyroid hormone concentrations were within the normal range, but the concentration of thyroglobulin was high because of the goitre. Two months later TSH was abnormally low and thyroxine was abnormally high, although the patient still showed no clinical signs of hyperthyroidism.

Two months later, when the cumulative dose of amiodarone was $40 \mathrm{~g}$, clinical overt thyrotoxicosis suddenly developed; the tender goitre was still present. Thyroid stimulating hormone (TSH) was undetectable; thyroxine (T4), free thyroxine (FT4), and triiodothyronine (T3) were raised; the thyroglobulin concentration had increased further. Concentrations of amiodarone and desethylamiodarone were in the therapeutic range (table 1). Because the erythrocyte sedimentation rate was normal and because the goitre had been present for more than two months we excluded the diagnosis of subacute thyroiditis of the Guervain type and diagnosed amiodarone induced thyrotoxicosis.

Treatment with carbimazole (40 $\mathrm{mg} /$ day) and potassium perchlorate ( $1 \mathrm{~g} /$ day) was started and treatment with amiodarone was continued. Clinical euthyroidism was achieved after 2 months, TSH was still undetectable, but T4 and T3 concentrations were almost normal. The TSH concentration became normal after 4 months. The thyroid gland was still slightly enlarged but no longer painful. The antithyroid medication was stopped. Although treatment with amiodarone continued clinical and biochemical thyroid dysfunction did not recur in the next 18 months. The goitre was no longer palpable. Ventricular tachycardia recurred and amiodarone and desethylamiodarone concentrations were below the therapeutic range of 0.2 and $0.4 \mathrm{mmol} / 1$ respectively. This confirmed our suspicion that the patient had stopped taking amiodarone between week $40-45$ of the follow up.

CASE 2 (TABLE 2)

A man born in 1936 had an inferolateral and right ventricular myocardial infarction com- plicated by cardiac aneurysm, severe mitral valve regurgitation, and poor left ventricular function. Late ventricular tachycardia was treated with several antiarrhythmic drugs (flecainide, chinidin, disopyramide) without success until amiodarone was started (800 $\mathrm{mg} /$ day). Before treatment with amiodarone the patient was clinically and biochemically euthyroid. When the dose of amiodarone was reduced to $200 \mathrm{mg}$ ventricular tachycardia recurred; a daily dose of $400 \mathrm{mg}$ prevented tachycardia.

After 37 months, when the cumulative amiodarone dose was $44 \mathrm{~g}$, overt amiodarone induced thyrotoxicosis developed. Serum T4 and FT4 concentrations were extremely high. One week later thyroxine and triiodothyronine concentrations had already fallen slightly. Treatment with carbimazole (40 $\mathrm{mg} /$ day) and potassium perchlorate ( $1 \mathrm{~g} /$ day) was started, while amiodarone medication was continued. The patient became clinically euthyroid after two months. When the thyroid stimulating hormone concentration became normal six months later, the anti-thyroid medication was stopped. Though he continued to take amiodarone, confirmed by measuring the serum concentrations of amiodarone and desethylamiodarone, thyroid dysfunction did not recur during the follow up of seven months. The patient died suddenly at home.

\section{Discussion}

Amiodarone induced thyrotoxicosis in these two patients was transient. It was successfully treated with a short course of antithyroid drugs while amiodarone was continued. When amiodarone is stopped because of amiodarone induced thyrotoxicosis life threatening tachycardia can recur. Under these circumstances total thyroidectomy has been advocated to allow treatment with amiodarone to continue. ${ }^{5}$ It is remarkable that a short course of antithyroid drugs restored euthyroidism, and that the patients remained euthyroid despite continuing treatment with amiodarone.

The mechanism of effects of amiodarone on the thyroid is multifactorial and largely 
unknown. Although auto-immune related thyrotoxicosis has been reported after amiodarone treatment, ${ }^{6}$ neither of our patients had a goiter or thyroid antibodies before amiodarone treatment and antibodies did not develop during follow up.

These data suggest that amiodarone induced thyrotoxicosis has a peculiar pathogenesis. When intrathyroidal amiodarone concentrations exceed a threshold, cell damage leads to thyrotoxicosis when the contents of the thyroid leak into the bloodstream. The intra-thyroidal concentration of amiodarone too would decrease, allowing repair and the restoration of euthyroidism. If this hypothesis is true, continuation of amiodarone treatment might eventually lead to a recurrence of thyrotoxicosis when the intrathyroidal amoidarone concentration again exceeds the threshold.
In our patients the follow up period was probably too short for a second period of thyrotoxicosis to develop.

1 Trip MD, Wiersinga WM, Plomp ThA. Incidence, predictability and pathogenesis of amiodarone induced thyrotoxicosis and hypothyroidism. Am f Med 1991;91: 507-11.

2 Smyrk TC, Goellner JR, Brennan MD, Carney JA Pathology of the thyroid in amiodarone-associated thyrotoxicosis. Am ₹ Surg Pathol 1987;11:197-204.

3 Martino E, Aghini-Lombardi F, Mariotti S. Treatment of amiodarone associated thyrotoxicosis by the simultaneous administration of potassium perchlorate and methious administration of potassium perchlorate

4 Reichert LJM, de Rooy HAM. Treatment of amiodarone induced hyperthyroidism with potassium perchlorate and methimazole during amiodarone treatment. $\mathrm{Br} M e d \mathcal{F}$ 1989;298:1547-8

5 Brennan MD, van Heerden JA, Carney JA. Amiodaroneassociated thyrotoxicosis (AAT): Experience with surgica management. Surgery 1987;102:1062-7.

6 Martino E, Macchia E, Aghhini-Lombardi F, et al. Is humoral thyroid autoimmunity relevant in Amiodaroneinduced thyrotoxicosis (AIIT)? Clin Endocrinol 1986;24: $627-33$.

\section{CORRECTION}

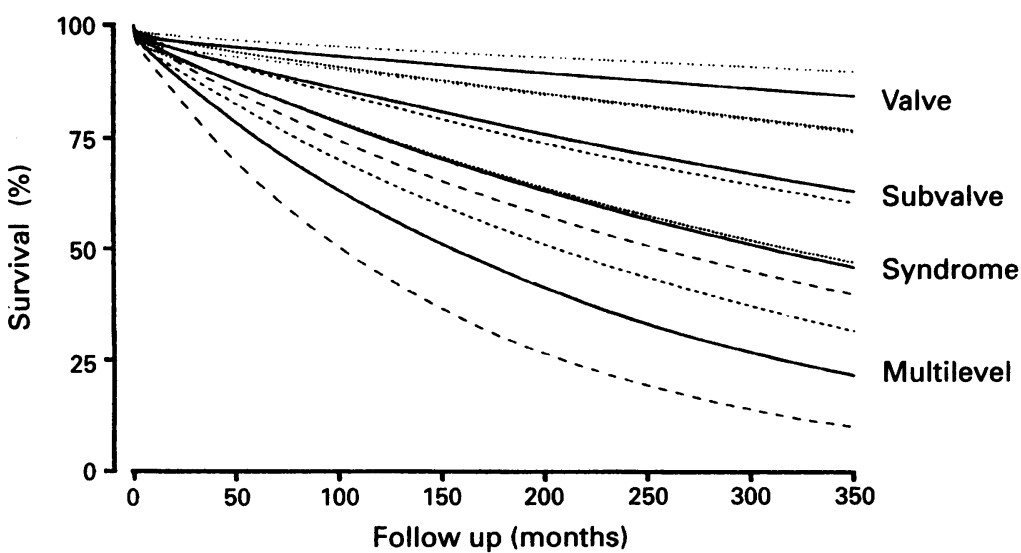

Figure 1 Predicted risk of death (and 70\% CIs) for a patient presenting at 13.9 months of age with moderate obstruction of the left ventricular outflow tract plotted against level of obstruction from a solution to equations developed by means of hazard analysis (appendix 1).

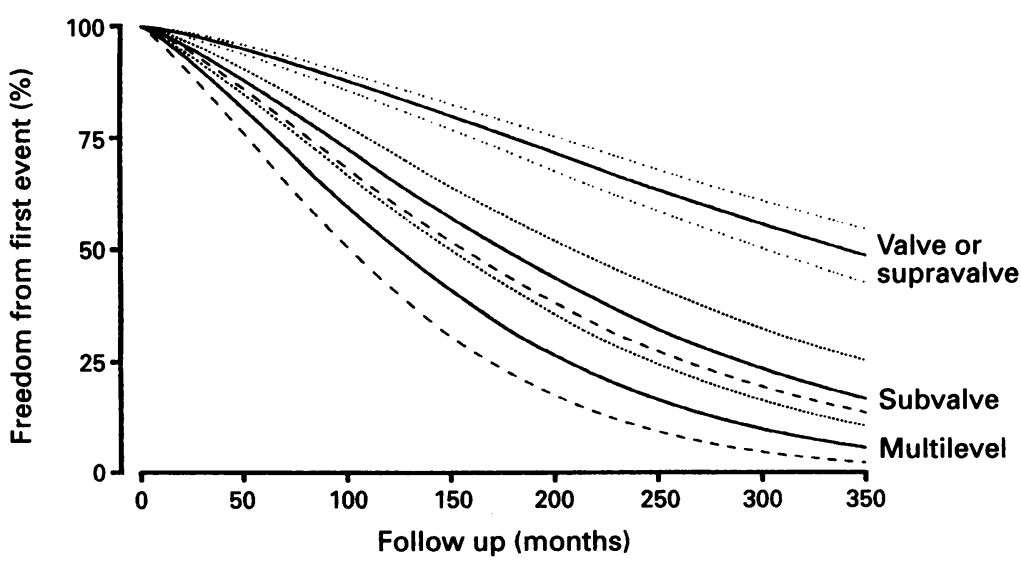

Figure 2 Predicted freedom from first clinical event (operation, balloon dilatation or endocarditis, and $70 \%$ CIs) for a patient presenting at 13.9 months of age with mild obstruction of left ventricular outflow tract without aortic regurgitation plotted against level of obstruction from equations developed by means of hazard analysis (appendix 1).
Incidence and prognosis of obstruction of the left ventricular outflow tract in Liverpool (1960-91): a study of 313 patients

D Kitchener, $M$ Fackson, N Malaiya, $K$ Walsh, I Peart, $R$ Arnold

We regret that owing to a printer's error figure 1 and figure 2 in this article in the June issue (Br Heart $\mathcal{F} 1994 ; 71: 588-95)$ appeared in the wrong order and with the wrong legends. The corrected versions are reprinted on the left. 